\title{
Medical utilization and cost outcomes for poststroke veterans who receive assistive technology devices from the Veterans Health Administration
}

\author{
Sandra L. Hubbard Winkler, PhD, OTR/L; ${ }^{1-2 *}$ Samuel Wu, PhD; ${ }^{1,3}$ Diane C. Cowper Ripley, PhD; ${ }^{1,3}$ Shirley \\ Groer, PhD; ${ }^{4}$ Helen Hoenig, $\mathbf{M D}^{\mathbf{5}}$ \\ ${ }^{1}$ Department of Veterans Affairs (VA) Rehabilitation Outcomes Research Center, Research Enhancement Award Program, \\ North Florida/South Georgia Veterans Health System, Gainesville, FL; ${ }^{2}$ Department of Occupational Therapy, College \\ of Public Health and Health Professions, University of Florida, Gainesville, FL; ${ }^{3}$ Department of Epidemiology and \\ Health Policy Research, College of Medicine, University of Florida, Gainesville, FL; ${ }^{4}$ James A. Haley Veterans' \\ Hospital, Tampa, FL; ${ }^{5}$ Durham VA Medical Center, Durham, NC; and Department of Medicine, Duke University, \\ Durham, NC
}

\begin{abstract}
The study objectives were to (1) advance understanding of the relationship between provision of assistive technology devices (ATDs) and healthcare consumption and outcomes in a system that does not limit provision of ATDs to in-home use and (2) determine how the provision of ATDs relates to inpatient/outpatient utilization and costs of services for veterans 12 months poststroke when controlling for casemix. This was a retrospective study using Department of Veterans Affairs administrative/workload databases to identify 12,046 veterans with stroke during fiscal years 2001 and 2002. Measures were functional gain, inpatient days, outpatient visits, and inpatient and outpatient costs during the first year poststroke. Motor gain for veterans receiving ATDs was higher than for veterans not receiving ATDs (20 vs 9 Functional Independence Measure points, $p<0.001$ ). Provision of a low-end manual wheelchair was associated with increased inpatient days and costs (both $p<0.001$ ). Provision of a power wheelchair was associated with increased inpatient $(p=0.03)$ and outpatient costs $(p<0.001)$. Provision of a scooter was associated with increased outpatient visits and outpatient costs (both $p<0.001)$. Scooters, walking aids, and power wheelchairs were associated with increased outpatient visits, perhaps functioning as outpatient/community enablers.
\end{abstract}

Key words: activities of daily living, assistive technology, cost, disability, healthcare utilization, rehabilitation, self-care, stroke, veterans, wheelchair.

\section{INTRODUCTION}

Adults $\geq 65$ years of age and people with physical disabilities are eligible for Medicare coverage of mobility

Abbreviations: ADL = activities of daily living, AFO = anklefoot orthosis, ATD = assistive technology device, CMS = Centers for Medicare and Medicaid Services, FIM = Functional Independence Measure, FRG = Function-Related Group, FY = fiscal year, $\mathrm{IADL}=$ instrumental $\mathrm{ADL}, \mathrm{KFO}=$ knee-foot orthosis, NPPD = National Prosthetics Patient Database, VA = Department of Veterans Affairs.

* Address all correspondence to Sandra L. Hubbard Winkler, PhD, OTR/L; RORC-REAP, North Florida/South Georgia Veterans Health System, 1601 SW Archer Road (151B), Gainesville, FL 32608-1197; 352-376-1611, ext 4928; fax: 352-271-4540. Email: Sandra.Winkler@va.gov DOI:10.1682/JRRD.2010.05.0081 
devices, such as wheelchairs, walkers, and scooters, for use in their homes. However, they are not eligible for coverage of mobility devices that are solely for mobility outside their homes [1]. In 2005, the Centers for Medicare and Medicaid Services (CMS) determined that mobility assistive equipment is reasonable and necessary for beneficiaries who have limitations in activities of daily living (ADL), e.g., toileting, feeding, dressing, grooming, and/or bathing [2]. Instrumental ADL (IADL) were excluded from coverage because they are not limited to functions in the home. This CMS determination conflicts with legislative actions that mandate individuals with disabilities be provided with the necessary supports to live as independently as possible in their communities [1]. Even though increased use of assistive technology devices (ATDs) has been cited as one of the reasons for decreasing disability [3-4] and has positively affected health-related costs by reducing falls and, subsequently, hospital admissions and institutional care [4-11], fewer than 50 percent of older adults with chronic disability and fewer than 25 percent of individuals with recent disabilities received ATDs [12]. Further, only 6 percent of community-dwelling Medicare beneficiaries received any ATDs from Medicare [13].

In contrast to the Medicare system, the Department of Veterans Affairs (VA) does not restrict provision of ATDs to veterans for use only in the home, thus offering an opportunity for us to examine the relationship between ATD provision and community outcomes. During VA fiscal year (FY) 2001, the VA National Prosthetics Patient Database (NPPD) listed 3.8 million devices and/or device repairs at a cost of $\$ 486$ million. The objective of our study was to advance understanding of the relationship between provision of ATDs and healthcare consumption and outcomes in a system that does not limit provision of ADL and mobility-related ATDs to in-home use. Our research question was "Controlling for case-mix, how does the provision of ATDs relate to inpatient and outpatient utilization and costs of services for veterans 12 months poststroke?”

"Each year, approximately 795,000 people experience a new or recurrent stroke. Approximately 610,000 of these are first attacks and 185,000 are recurrent attacks. Mortality data from 2006 indicate that stroke accounted for approximately 1 of every 18 deaths in the United States. On average, every 40 seconds, someone in the United States has a stroke" [14]. As the population ages, the social and economic burden of stroke is expected to increase [15]. An estimated 15,000 veterans are hospitalized in the VA for a new stroke each year [16]. Stroke and related diseases consume about 5 percent of VA resources [17]. In Canada, 43 percent of individuals 1-month poststroke were using a mobility-related ATD. Similarly, 40 percent of our poststroke veteran cohort received an ATD [18].

We are developing our methods to address equitable access to ATDs and services within the poststroke cohort for two reasons. First, veterans poststroke receive a high percentage of the ATDs provided by the VA [19]; i.e., stroke was the second most frequent primary diagnosis of veterans who received wheeled mobility devices, second only to chronic obstructive pulmonary disease/congestive heart failure. Second, stroke requires the most complex, challenging research design because of the recovery curve [20-21] and changing ATD needs. We began with a more challenging design and will apply this design to more static conditions (e.g., spinal cord injury) and progressive conditions (e.g., multiple sclerosis or polymyositis), in which individuals have the opportunity to consider (not necessarily accept) options.

\section{DATA PREPARATION AND ANALYSES}

An International Classification of Diseases-9th Revision code search of two national VA databases, the Functional Status Outcomes Database and the Medical SAS data sets [22], was used to identify 6,675 unique veterans who were provided VA care for stroke during FY01 and 6,689 unique veterans during FY02. Specific details have been previously published [18]. After data cleaning, the final study cohort included 12,046 unique veterans.

Data on veteran function, from Functional Independence Measure (FIM) scores [23], were acquired from the Functional Status Outcomes Database. FIM scores were only available for 5,519 (46\%) of veterans in our cohort because the VA clinical directive mandating FIM assessment for veterans poststroke was only implemented in FY01. Inpatient and outpatient utilization and diagnoses codes for comorbidity measurement were obtained from the Medical SAS data sets. Cost data for FY01 to FY03 were obtained from VA Decision Support System Medical SAS cost extracts for inpatient, outpatient pharmacy, and outpatient nonpharmacy files for the first occurring stroke event and 12 months of follow-up. 
ATD data were acquired from the NPPD and were limited to devices prescribed within 1 year of the index stroke admission in the following categories: (1) standard (low-end) manual wheelchairs; (2) lightweight and hemi rehabilitation (mid-range) manual wheelchairs; (3) ultralight manual (high-end) wheelchairs; (4) power wheelchairs; (5) power scooters; (6) ankle-foot orthoses (AFOs)/kneefoot orthoses (KFOs); and (7) walkers, crutches, and canes.

Bivariate ( $t$-test) and multivariate (analysis of covariance) analyses were performed. Multivariate analyses were limited to the subset of the study cohort $\geq 65$ years at the index stroke admission. The independent variable was provision of ATDs. Outcome variables were inpatient days and outpatient visits and costs of VA services poststroke. Because the cost data were skewed to the right, the natural log of each cost data value was used. Covariates for case-mix adjustment included age at index stroke; death during the 1-year follow-up period after the index stroke admission; sex, if the admission source was from a nursing home; marital status; hemorrhagic stroke; dysphasia; mechanical ventilation; treatment in a specialty rehabilitation unit; severity of disability; and comorbidity. The FIM Function-Related Groups (FRGs) system was used to control for severity of disability [2427]. FRGs were based on the index stroke admission FIM score acquired from the Functional Status Outcomes Database. Of veterans 65 years or older, 5,474 had FIM scores. A challenge in ATD research is that individuals usually receive more than one ATD. To isolate and characterize associations with device prescriptions, we created a variable for each of our eight ATD categories. We assigned veterans who received only one ATD to the appropriate category. We created a ninth ATD variable for veterans who received more than one device. Data for other covariates were acquired from the Medical SAS data sets. The Elixhauser Index was used to measure comorbidity [22].

\section{RESULTS}

Of our population-based cohort of 12,046 unique veterans $[18,28]$ with an index stroke during FY01 to FY02, 60 percent $(n=7,204)$ received ATDs. The population was typically male (98\%). The mean age was 69 years for veterans who received ATDs and 68 years for veterans who did not receive ATDs. Of the cohort, 49 percent was married; 51 percent of veterans who received ATDs and 46 percent of veterans who did not receive ATDs were married. Hispanics and African Americans tended proportionally to receive devices at a slightly higher rate than whites. Patients with more severe disability (FRG1) tended to receive devices more often (13\% for FRG1 vs $4 \%-8 \%$ for all other FRGs).

Table 1 presents the results of the bivariate analyses comparing veterans who did and did not receive ATDs. The admission FIM Motor score and the FIM gain (discharge - admission) were significantly different between the two groups. The functional gain (Motor) for veterans who received ATDs was much higher than for veterans who did not receive ATDs (19.7 FIM Motor points vs 9.4 FIM Motor points, $p<0.001)$. For veterans who did not receive ATDs, 15 percent died as a result of the index stroke and 21 percent died during the 12-month followup period. The index length of stay, number of inpatient days and outpatient visits during the 12-month follow-up period, and 12-month follow-up costs were higher for veterans who received ATDs. Veterans who died during the acute hospitalization for their index stroke were omitted from further analyses.

Table 2 presents the beta coefficients and $p$-values for the multivariate analyses. First, the covariate data are presented: demographic and severity of disability (FRG) [27] variables. Younger age was, for example, significantly associated with inpatient and outpatient days and costs. Index stroke admission from a skilled nursing facility was positively associated with increased inpatient and outpatient days. All levels of severity of disability (FRG) were significantly associated with a larger number of inpatient days and greater cost when compared with the referent, FRG9, the least disabled group. The highest number of inpatient days was associated with severe motor disability and being over the age of 74 with relatively high cognitive function (FRG3). The next highest number of inpatient days was associated with severe motor disability and age 16 to 74 (FRG1) followed by severe motor disability over the age of 74 with relatively low cognitive function (FRG2). FRG2 was associated with fewer outpatient visits while FRG7 (mild-moderately impaired motor function and relatively low cognitive function) was associated with increased outpatient visits.

Predictor variable data (ATD categories) are also presented in Table 2. Provision of a standard manual wheelchair; a rehabilitation manual wheelchair; a walker, cane, or crutch; or multiple ATDs was significantly associated 
JRRD, Volume 48, Number 2, 2011

Table 1.

Bivariate comparisons of function, discharge location, length of stay, utilization, and costs for veterans who did or did not receive assistive technology devices.

\begin{tabular}{|c|c|c|c|}
\hline Variable & $\begin{array}{c}\text { Did Not Receive Device } \\
(n=4,842)\end{array}$ & $\begin{array}{c}\text { Received Device } \\
\quad(n=7,204)\end{array}$ & $p$-Value \\
\hline \multicolumn{4}{|l|}{$\overline{\text { FIM Motor Score }}$} \\
\hline Admission $^{*}$ & 53.2 & 46.5 & $<0.001$ \\
\hline Discharge $^{*}$ & 62.2 & 63.6 & 0.097 \\
\hline FIM Gain & 9.4 & 19.7 & $<0.001$ \\
\hline \multicolumn{4}{|l|}{ Discharge Status (\%) } \\
\hline Died (index stroke) & 14.6 & 3.3 & $<0.001$ \\
\hline Community & 70.8 & 74.5 & \\
\hline Nursing Home & 10.6 & 17.6 & \\
\hline Other & 18.7 & 7.9 & \\
\hline Index Length of Stay (d) & 10.9 & 18.3 & $<0.001$ \\
\hline Died During 12 Mo Follow-Up Period (\%) & 21.0 & 7.3 & $<0.001$ \\
\hline Total Inpatient Days: 12 Mo Follow-Up (d) & 21.1 & 44.1 & $<0.001$ \\
\hline Total Outpatient Visits: 12 Mo Follow-Up & 15.9 & 23.1 & $<0.001$ \\
\hline Total VA Costs (\$) & 26,170 & 46,550 & $<0.001$ \\
\hline
\end{tabular}

with more inpatient days. Provision of a scooter; a walker, cane, or crutch; or multiple ATDs was significantly associated with more outpatient visits. Provision of a standard manual wheelchair; a rehabilitation manual wheelchair; a power wheelchair; a walker, cane, or crutch; or multiple ATDs was significantly associated with inpatient costs over the 12-month poststroke period. Provision of a power wheelchair; a scooter; a walker, cane, or crutch; or multiple ATDs was significantly associated with increased outpatient costs.

A second way of interpreting the multivariate data is by device rather than by utilization outcome. Lower-end manual wheelchairs had significant associations only with inpatient utilization (costs and days), power wheelchairs only with higher costs (inpatient and outpatient), and scooters only with outpatient utilization (visits and costs).

\section{DISCUSSION}

This study identified 12,046 veterans who experienced a stroke in FY01 or FY02 and examined bivariate relationships between ATD provision and functional gain, inpatient and outpatient care, and costs. We then created five models with inpatients days, inpatient dollars, outpatient visits, outpatient dollars, and discharge status as out- come variables. We found that provision of mobility ATDs is associated with motor gain and that provision of a scooter is associated with more outpatient visits, when controlling for both disability and comorbidity.

\section{Length of Stay}

Length of stay, because of its effect on cost, has been the focus of much research [29] but not with regards to the effects of ATDs. The only other known study to investigate length of stay in the context of ATD provision was Garber et al., who looked at "rehabilitation" length of stay for poststroke veteran wheelchair users [30]. We examined length of stay in the acute care, not rehabilitation, setting, so it is not surprising that our acute care length of stay at 11 days for veterans who received ATD(s) and 18 days for veterans who did not receive ATD(s) was much shorter than that of Garber et al., who reported length of stay for wheelchair recipients of 73 days [30]. The reasons for these differences may be the inclusion of rehabilitation length of stay, which is frequently longer than acute length of stay [29] and that the Garber et al. [30] data were collected earlier (1989-99) than our data. Rehabilitation lengths of stay were typically longer during the period when Garber et al. collected their data [31-32].

Our acute care length of stay results for veterans with an acute stroke were similar to other studies. For example, 
Table 2.

Ordinary least squares regression results (coefficients) for demographic, patient function (covariates), and VA device prescription (predictor variable) for five dependent variables: inpatient days, outpatient visits, inpatient and outpatient costs, and discharge to community (logistic regression). Only statistically significant beta coefficients ( $p$-value) at alpha $<0.05$ are shown.

\begin{tabular}{|c|c|c|c|c|}
\hline \multirow[b]{2}{*}{ Variable } & \multicolumn{4}{|c|}{ Outcome Variable } \\
\hline & $\begin{array}{l}\text { Inpatient Days } \\
\quad(n=5,474)\end{array}$ & $\begin{array}{l}\text { Inpatient Costs }(\$) \\
(n=5,474)\end{array}$ & $\begin{array}{l}\text { Outpatient Visits } \\
\quad(n=5,054)\end{array}$ & $\begin{array}{l}\text { Outpatient Costs (\$) } \\
\quad(n=5,154)\end{array}$ \\
\hline \multicolumn{5}{|l|}{ Covariates } \\
\hline Age & $-0.3(0.003)$ & $-0.004(0.002)$ & $-0.2(<0.001)$ & $-0.006(<0.001)$ \\
\hline Died & $-8.8(0.005)$ & NS & $-11.9(<0.001)$ & $-1.2(<0.001)$ \\
\hline Male & NS & NS & $-6.2(<0.001)$ & $-0.3(0.01)$ \\
\hline Nursing Home PTA & $18.8(0.006)$ & NS & $12.3(<0.001)$ & NS \\
\hline Married & $-3.5(0.03)$ & $-0.1(<0.001)$ & $2.6(<0.001)$ & $0.1(0.007)$ \\
\hline Hemorrhagic Stroke & NS & NS & NS & NS \\
\hline Dysphagia & NS & $0.1(0.01)$ & NS & NS \\
\hline On Ventilator & NS & $0.6(<0.001)$ & NS & $0.4(0.002)$ \\
\hline Treated in Acute Rehabilitation & $7.2(<0.001)$ & $0.4(<0.001)$ & $2.8(<0.001)$ & $0.1(0.01)$ \\
\hline FRG1 & $40.8(<0.001)$ & $1.2(<0.001)$ & NS & $-0.2(0.002)$ \\
\hline FRG2 & $38.8(<0.001)$ & $1.1(<0.001)$ & $-3.7(0.02)$ & $-0.4(<0.001)$ \\
\hline FRG3 & $45.5(<0.001)$ & $1.2(<0.001)$ & NS & NS \\
\hline FRG4 & $28.4(<0.001)$ & $1.0(<0.001)$ & NS & NS \\
\hline FRG5 & $23.7(<0.001)$ & $0.8(<0.001)$ & NS & NS \\
\hline FRG6 & $13.4(<0.001)$ & $0.6(<0.001)$ & NS & NS \\
\hline FRG7 & $11.6(<0.001)$ & $0.5(<0.001)$ & $3.7(0.002)$ & NS \\
\hline FRG8 & $8.6(0.02)$ & $0.3(<0.001)$ & NS & NS \\
\hline $\begin{array}{l}\text { Elixhauser Index Number of Significant } \\
\text { Variables }\end{array}$ & 3 & 2 & 1 & 1 \\
\hline \multicolumn{5}{|l|}{ Predictor Variables } \\
\hline One VA AFO/KFO Only & $16.0(0.03)$ & $0.2(0.04)$ & NS & NS \\
\hline One VA Std Manual W/C Only & $16.3(<0.001)$ & $0.3(<0.001)$ & NS & NS \\
\hline One VA High-End Manual W/C Only & NS & NS & NS & $1.0(0.006)$ \\
\hline One VA Rehabilitation Manual W/C Only & $24.5(<0.001)$ & $0.4(<0.001)$ & NS & NS \\
\hline One VA Power W/C Only & NS & $0.4(0.03)$ & NS & $1.0(<0.001)$ \\
\hline One VA Scooter Only & NS & NS & $17.9(<0.001)$ & $1.0(<0.001)$ \\
\hline One VA Walker, Crutch, or Cane Only & $4.3(0.03)$ & $0.2(<0.001)$ & $4.1(<0.001)$ & $0.3(<0.001)$ \\
\hline VA Multidevice Exclusion AFO/KFO & $14.5(<0.001)$ & $0.4(<0.001)$ & $7.3(<0.001)$ & $0.5(<0.001)$ \\
\hline Adjusted $R^{2}$ & 0.11 & 0.30 & 0.10 & 0.12 \\
\hline
\end{tabular}

$\overline{\mathrm{AFO}}=$ ankle-foot orthosis, FRG $=$ Function-Related Group, KFO $=$ knee-foot orthosis, NS $=$ not significant, $\mathrm{PTA}=$ prior to admission, Std $=$ standard, VA $=$ Department of Veterans Affairs, W/C = wheelchair.

Jia et al. found the mean length of acute stay for veterans with stroke was 20 days [33]. Some studies of acute hospitalization for stroke report lengths of stay ranging from 4 to 8 days (nonveteran facilities) [34-35]; however, Hoh et al. reported a mean length of stay of 19 to 21 days for ruptured aneurysms compared with 4 to 9 days for unruptured aneurysms (also nonveteran facilities) [36]. Investigators have failed to find a significant difference in length of stay for individuals with stroke in VA versus Medicare facilities [33,37].
It is well known that physical function is a strong predictor of acute length of stay [29,38]. Our bivariate analyses showed that veterans who received ATDs had a longer length of stay and more severe disability at admission than veterans who did not receive ATDs. Therefore, our multivariate models, which controlled for severity of disability, still showed that low- and moderate-end manual wheelchairs, walkers, AFOs/KFOs, and multiple ATDs were associated with longer inpatient stay and admission to inpatient rehabilitation. Similarly, we found that outpatient visits after an acute stroke were related to 
ATD provision, even after controlling for functional skills on admission. Specifically, provision of a scooter or walking device was associated with outpatient visits, indicating these devices may enable better outpatient healthcare.

\section{Functional Gain}

More revealing than function at admission was functional gain during the hospital episode of care. In our study, veterans who received ATDs had a significantly higher motor gain (20 out of 91 possible FIM Motor points, acute length of stay 18 days) than veterans who did not receive ATDs (9 out of 91 possible FIM Motor points, acute length of stay 11 days). Mountain et al. found a similar trend in admission to discharge gain in the "rehabilitation" environment, with wheelchair users experiencing a mean total FIM gain of 24 points (126 possible points, mean rehabilitation length of stay of 41 days) compared with a gain of 16 points (126 possible for points, mean rehabilitation length of stay of 27 days) for nonwheelchair users [39]. Granger et al. and Ottenbacher et al. also looked at functional gain in a 2001 national stroke cohort but did not consider provision of ATDs in their analyses [31-32]. While findings of functional gain by Granger et al. are comparable to ours (21 FIM Motor points during inpatient "rehabilitation" with a mean length of stay of 20 days compared with our mean gain of 20 FIM Motor points during "acute" inpatient stay with a mean length of stay of 18 days) [31], Granger et al. did not examine the effect of ATD provision. Ottenbacher et al. performed a similar analysis using total FIM score [32]; because our study used only FIM Motor scores, functional gain cannot be compared. The observed increase in functional gain in our study may be attributed to the ATDs and/or increased length of stay in persons receiving ATDs and the natural course of stroke recovery; future studies should tease out the causal mechanisms underlying the important relationship between ATD provision and better functional outcomes.

\section{Discharge Status}

Our study failed to find an overall significant association between provision of $\operatorname{ATD}(\mathrm{s})$ and discharge status. That is, the pattern of provision of ATDs for veterans discharged from acute to home, community, or rehabilitation was similar to the provision of ATDs for veterans discharged to a nursing home or institution. There was one exception: a higher percentage of veterans who received a walker, cane, or crutch were discharged to the community. Other studies have shown that functional status, social situation prior to stroke, and level of cognition predict discharge status [40-42]; no studies of discharge status were found that included provision of ATDs.

\section{Limitations}

A limitation to this study was that administrative data were used. Administrative data are the by-product of running a healthcare system [43]. A disadvantage of using administrative data is that the data may be coded inconsistently or erroneously and may be incomplete [44]. There are, however, advantages of using administrative data: administrative data include a large number of people, track service utilization, and are already in existence [43]. In previous studies, we have shown that once data cleaning, considered routine in large data studies, is performed, NPPD data are valid for identifying devices provided to veterans [18-19,28,45-47]. Another limitation of this study is that the ATDs provided may not have been related to stroke; the ATD(s) could have been prescribed for another disease or injury. Finally, this is a cohort study and aspects of the study are cross-sectional in nature. We cannot be sure within this database when ATDs were provided in relationship to specific improvements in function or how they relate to clinical decisionmaking. Thus, we cannot be sure of the causal relationship between ATD provision and the various outcomes.

Despite the study limitations, we think our findings have important policy implications for the VA and the CMS. Our findings are pertinent to Medicare policy in so far as Medicare coverage for mobility devices, such as wheelchairs and walkers, is limited to persons who will use the device in their homes. Unlike those covered by the VA, these individuals cannot get coverage for mobility devices needed for IADL because these activities are not limited to mobility functions "in the home" [1-2]. We know that the use of ATDs is associated with decreased disability [3-4], which reduces falls and subsequent hospital admissions/institutional care [4-11] and, thus, healthcare costs. It makes sense then, in the context of healthcare reform (reduction in emergent care and rehospitalization [48-49], implementation of the medical home model [50]) that the savings be reinvested in expanding the provision of ATDs. Expansion of provision of ATDs to maintain independence, aging in place, and quality of life is in the best interest of elderly patients, who have the technology to age in place (Wi-Fi 
exercise, robot vacuum cleaners), and society. Social isolation can lead to a number of major health problems (depression, substance abuse, etc.) and can greatly reduce quality of life and well-being [51]. Even the more expensive ATDs, e.g., custom power wheelchairs, are less costly than residential skilled nursing care.

\section{CONCLUSIONS}

Our findings show that provision of mobility ATDs to veterans by the VA predicts greater functional gain while in the hospital and, most notably, greater outpatient visits, when both disability and comorbidity were controlled for, indicating that these devices may enable better outpatient healthcare. However, the ATD recipients did have longer lengths of stay so future studies may want to focus on how to meet ATD care needs more efficiently.

\section{ACKNOWLEDGMENTS}

\author{
Author Contributions: \\ Study concept and design: S. L. Hubbard Winkler. \\ Acquisition of data: S. L. Hubbard Winkler. \\ Analysis and interpretation of data: S. L. Hubbard Winkler, \\ S. Wu, D. C. Cowper Ripley, H. Hoenig, S. Groer. \\ Drafting of manuscript: S. L. Hubbard Winkler. \\ Critical revision of manuscript for important intellectual content: \\ S. Hubbard Winkler, S. Wu, H. Hoenig. \\ Statistical analysis: S. Wu. \\ Obtained funding: S. L. Hubbard Winkler. \\ Study supervision: S. L. Hubbard Winkler.
}

Financial Disclosures: The authors have declared that no competing interests exist.

Funding/Support: This material was based on work supported by VA Rehabilitation Research and Development Service (grant F3736R to principal investigator Dean Reker [retired]).

Institutional Review: This was a retrospective population-based study approved by the Kansas City VA Medical Center and the VA Pittsburgh and North Florida/South Georgia Veterans Healthcare Systems Institutional Review Boards/VA Human Subjects Subcommittees.

\section{REFERENCES}

1. Medicare Rights Center. Forcing isolation: Medicare's “in the home” coverage standard for wheelchairs. Care Manag J. 2005;6(1):29-37. [PMID: 16447855]

DOI:10.1891/cmaj.2005.6.1.29

2. Phurrough S, Jacques L, Feinglass S, Daily K. Decision memo for mobility assistive equipment. Washington (DC):
Centers for Medicare and Medicaid Services (US); 2005. Report No.: CAG-00274N.

3. Cutler DM. Declining disability among the elderly. Health Aff (Millwood). 2001;20(6):11-27. [PMID: 11816649] DOI:10.1377/hlthaff.20.6.11

4. Allaire SH, LaValley MP, Evans SR, O’Connor GT, KellyHayes M, Meenan RF, Levy D, Felson DT. Evidence for decline in disability and improved health among persons aged 55 to 70 years: The Framingham Heart Study. Am J Public Health. 1999;89(11):1678-83. [PMID: 10553388] DOI:10.2105/AJPH.89.11.1678

5. Mann WC, Ottenbacher KJ, Fraas L, Tomita M, Granger $\mathrm{CV}$. Effectiveness of assistive technology and environmental interventions in maintaining independence and reducing home care costs for the frail elderly. A randomized controlled trial. Arch Fam Med. 1999;8(3):210-17.

[PMID: 10333815]

DOI:10.1001/archfami.8.3.210

6. Close J, Ellis M, Hooper R, Glucksman E, Jackson S, Swift C. Prevention of falls in the elderly trial (PROFET): A randomised controlled trial. Lancet. 1999;353(9147):93-97. [PMID: 10023893] DOI:10.1016/S0140-6736(98)06119-4

7. Cumming RG, Thomas M, Szonyi G, Salkeld G, O’Neil E, Westbury C, Frampton G. Home visits by an occupational therapist for assessment and modification of environmental hazards: A randomized trial of falls prevention. J Am Geriatr Soc. 1999;47(12):1397-1402. [PMID: 10591231]

8. Gill TM. Preventing falls: To modify the environment or the individual? J Am Geriatr Soc. 1999;47(12):1471-72. [PMID: 10591245]

9. Bendixen RM, Levy CE, Olive ES, Kobb RF, Mann WC. Cost effectiveness of a telerehabilitation program to support chronically ill and disabled elders in their homes. Telemed J E Health. 2009;15(1):31-38. [PMID: 19199845$]$ DOI:10.1089/tmj.2008.0046

10. Harris JE, Eng JJ, Marigold DS, Tokuno CD, Louis CL. Relationship of balance and mobility to fall incidence in people with chronic stroke. Phys Ther. 2005;85(2):150-58. [PMID: 15679466]

11. Weerdesteyn V, De Niet M, Van Duijnhoven HJ, Geurts AC. Falls in individuals with stroke. J Rehabil Res Dev. 2008;45(8):1195-1213. [PMID: 19235120] DOI:10.1682/JRRD.2007.09.0145

12. Iwashyna TJ, Christie JD. Low use of durable medical equipment by chronically disabled elderly. J Pain Symptom Manage. 2007;33(3):324-30. [PMID: 17349502]

DOI:10.1016/j.jpainsymman.2006.08.012

13. Wolff JL, Agree EM, Kasper JD. Wheelchairs, walkers, and canes: What does Medicare pay for, and who benefits? Health Aff (Millwood). 2005;24(4):1140-49.

[PMID: 16012154]

DOI:10.1377/hlthaff.24.4.1140 
14. Writing Group Members; Lloyd-Jones D, Adams RJ, Brown TM, Carnethon M, Dai S, De Simone G, Ferguson TB, Ford E, Furie K, Gillespie C, Go A, Greenlund K, Haase N, Hailpern S, Ho PM, Howard V, Kissela B, Kittner S, Lackland D, Lisabeth L, Marelli A, McDermott MM, Meigs J, Mozaffarian D, Mussolino M, Nichol G, Roger VL, Rosamond W, Sacco R, Sorlie P, Roger VL, Thom T, Wasserthiel-Smoller S, Wong ND, Wylie-Rosett J; American Heart Association Statistics Committee and Stroke Statistics Subcommittee. Heart disease and stroke statistics2010 update: A report from the American Heart Association. Circulation. 2010;121(7):e46-e215. [PMID: 20019324

15. Duncan PW, Horner RD, Reker DM, Samsa GP, Hoenig H, Hamilton B, LaClair BJ, Dudley TK. Adherence to postacute rehabilitation guidelines is associated with functional recovery in stroke. Stroke. 2002;33(1):167-77.

[PMID: 11779907]

DOI:10.1161/hs0102.101014

16. Oddone E, Brass LM, Booss J, Goldstein L, Alley L, Horner R, Rosen A, Kaplan L. Quality enhancement research initiative in stroke: Prevention, treatment, and rehabilitation. Med Care. 2000;38(6 Suppl 1):I92-I104.

[PMID: 10843274$]$

DOI:10.1097/00005650-200006001-00010

17. Department of Veterans Affairs (VA) San Antonio Cochrane Center. Acute stroke treatment. Perry Point (MD): VA Health Services Research and Development: Management Decision and Research Center, Practice Matters; $1997 ; 2(1): 1-6$.

18. Hubbard Winkler SL, Cowper Ripley DC, Wu S, Reker DM, Vogel B, Fitzgerald SG, Mann WC, Hoenig H. Demographic and clinical variation in Veterans Health Administration provision of assistive technology devices to veterans poststroke. Arch Phys Med Rehabil. 2010;91(3): 369-77. [PMID: 20298826]

DOI:10.1016/j.apmr.2009.10.028

19. Hubbard SL, Fitzgerald SG, Vogel B, Reker DM, Cooper RA, Boninger ML. Distribution and cost of wheelchairs and scooters provided by Veterans Health Administration. J Rehabil Res Dev. 2007;44(4):581-92. [PMID: 18247255] DOI:10.1682/JRRD.2006.10.0136

20. Duncan PW, Goldstein LB, Horner RD, Landsman PB, Samsa GP, Matchar DB. Similar motor recovery of upper and lower extremities after stroke. Stroke. 1994;25(6): 1181-88. [PMID: 8202977]

21. Duncan PW, Goldstein LB, Matchar D, Divine GW, Feussner J. Recovery of motor function after stroke. Outcome assessment and sample size requirements. Stroke. 1992;23; 1084-89.

22. VA Information Resource Center (VIReC) [Internet]. Washington (DC): Department of Veterans Affairs; 2008 [updated 2010 Oct 6; cited 2008 Mar 27]. Available from: http://www.virec.research.va.gov/index.htm.
23. About the FIM system [Internet]. Amherst (NY): Uniform Data System for Medical Rehabilitation; 2002. Available from: http://www.udsmr.org/WebModules/FIM/Fim About.aspx.

24. Vogel WB, Berlowitz DR, Tsilimingras D, Hoenig HM, Young LJ, Cowper DC, Duncan PW, Wing KL. Functionbased risk adjustment in statistical models: Systems vs. components. Proceedings of the HSR\&D National Meeting 2007: Managing recovery and health through the continuum of care; 2007 Feb 21-23; Arlington, VA. Washington (DC): Department of Veterans Affairs; 2007.

25. Granger CV. Quality and outcome measures for rehabilitation programs [Internet]. Omaha (NE): e-Medicine; 2007 [updated 2008 Aug 20; cited 2007 Dec 26]. Available from: http://www.emedicine.com/pmr/topic155.htm.

26. Stineman MG, Escarce JJ, Goin JE, Hamilton BB, Granger CV, Williams SV. A case-mix classification system for medical rehabilitation. Med Care. 1994;32(4):366-79.

[PMID: 8139301] DOI:10.1097/00005650-199404000-00005

27. Stineman MG, Tassoni CJ, Escarce JJ, Goin JE, Granger CV, Fiedler RC, Williams SV. Development of functionrelated groups version 2.0: A classification system for medical rehabilitation. Health Serv Res. 1997;32(4):529-48. [PMID: 9327817]

28. Winkler SL, Vogel WB, Hoenig H, Ripley DC, Wu S, Fitzgerald SG, Mann WC, Reker DM. Cost, utilization, and policy of provision of assistive technology devices to veterans poststroke by Medicare and VA. Med Care. 2010;48(6): 558-62. [PMID: 20125048] DOI:10.1097/MLR.0b013e3181bd4a11

29. Koton S, Bornstein NM, Tsabari R, Tanne D; NASIS Investigators. Derivation and validation of the prolonged length of stay score in acute stroke patients. Neurology. 2010;74(19):1511-16. [PMID: 20458067] DOI:10.1212/WNL.0b013e3181dd4dc5

30. Garber SL, Bunzel R, Monga TN. Wheelchair utilization and satisfaction following cerebral vascular accident. J Rehabil Res Dev. 2002;39(4):521-34. [PMID: 17638149]

31. Granger CV, Markello SJ, Graham JE, Deutsch A, Ottenbacher KJ. The uniform data system for medical rehabilitation: Report of patients with stroke discharged from comprehensive medical programs in 2000-2007. Am J Phys Med Rehabil. 2009;88(12):961-72. [PMID: 19935180] DOI:10.1097/PHM.0b013e3181c1ec38

32. Ottenbacher KJ, Smith PM, Illig SB, Linn RT, Ostir GV, Granger CV. Trends in length of stay, living setting, functional outcome, and mortality following medical rehabilitation. JAMA. 2004;292(14):1687-95. [PMID: 15479933]

33. Jia H, Zheng Y, Reker DM, Cowper DC, Wu SS, Vogel WB, Young GC, Duncan PW. Multiple system utilization and mortality for veterans with stroke. Stroke. 2007;38(2): 355-60. [PMID: 17194888] DOI:10.1161/01.STR.0000254457.38901.fb 
34. Ovbiagele B. Nationwide trends in in-hospital mortality among patients with stroke. Stroke. 2010;41(8):1748-54. [PMID: 20558829] DOI:10.1161/STROKEAHA.110.585455

35. Tong X, Kuklina EV, Gillespie C, George MG. Medical complications among hospitalizations for ischemic stroke in the United States from 1998 to 2007. Stroke. 2010;41(5): 980-86. [PMID: 20203317] DOI:10.1161/STROKEAHA.110.578674

36. Hoh BL, Chi YY, Lawson MF, Mocco J, Barker FG 2nd. Length of stay and total hospital charges of clipping versus coiling for ruptured and unruptured adult cerebral aneurysms in the Nationwide Inpatient Sample Database 2002 to 2006. Stroke. 2010;41(2):337-42. [PMID: 20044522] DOI:10.1161/STROKEAHA.109.569269

37. Silber JH, Rosenbaum PR, Rosen AK, Romano PS, Itani KM, Cen L, Mi L, Halenar MJ, Even-Shoshan O, Volpp KG. Prolonged hospital stay and the resident duty hour rules of 2003. Med Care. 2009;47(12):1191-1200. [PMID: 19786912] DOI:10.1097/MLR.0b013e3181adcbff

38. Chang KC, Tseng MC, Weng HH, Lin YH, Liou CW, Tan TY. Prediction of length of stay of first-ever ischemic stroke. Stroke. 2002;33(11):2670-74. [PMID: 12411659] DOI:10.1161/01.STR.0000034396.68980.39

39. Mountain AD, Kirby RL, MacLeod DA, Thompson K. Rates and predictors of manual and powered wheelchair use for persons with stroke: A retrospective study in a Canadian rehabilitation center. Arch Phys Med Rehabil. 2010;91(4):639-43. [PMID: 20382299] DOI:10.1016/j.apmr.2009.11.025

40. Chumney D, Nollinger K, Shesko K, Skop K, Spencer M, Newton RA. Ability of Functional Independence Measure to accurately predict functional outcome of stroke-specific population: Systematic review. J Rehabil Res Dev. 2010; 47(1):17-29. [PMID: 20437324] DOI:10.1682/JRRD.2009.08.0140

41. Denti L, Agosti M, Franceschini M. Outcome predictors of rehabilitation for first stroke in the elderly. Eur J Phys Rehabil Med. 2008;44(1):3-11. [PMID: 18385622]

42. Reistetter TA, Graham JE, Deutsch A, Granger CV, Markello S, Ottenbacher KJ. Utility of functional status for classifying community versus institutional discharges after inpatient rehabilitation for stroke. Arch Phys Med Rehabil. 2010;91(3):345-50. [PMID: 20298822]

DOI:10.1016/j.apmr.2009.11.010

43. Iezzoni LI. Using administrative data to study persons with disabilities. Milbank Q. 2002;80(2):347-79.

[PMID: 12101876$]$

DOI:10.1111/1468-0009.t01-1-00007

44. Cowper DC, Hynes DM, Kubal JD, Murphy PA. Using administrative databases for outcomes research: Select examples from VA Health Services Research and Develop- ment. J Med Syst. 1999;23(3):249-59. [PMID: 10554740] DOI:10.1023/A:1020579806511

45. Fitzgerald SG, Reker D. Assessment of the National Prosthetics Patient Database: Preliminary studies of validity. Pittsburgh (PA): Department of Veterans Affairs; 2003.

46. Hubbard SL, Fitzgerald SG, Reker DM, Boninger ML, Cooper RA, Kazis LE. Demographic characteristics of veterans who received wheelchairs and scooters from Veterans Health Administration. J Rehabil Res Dev. 2006;43(7): 831-44. [PMID: 17436170]

DOI:10.1682/JRRD.2005.11.0174

47. Hubbard Winkler SL, Fitzgerald SG, Boninger ML, Cooper RA. Relationship between quality of wheelchair and quality of life. Top Geriatr Rehabil. 2008;24(3):264-78.

48. Singh SN. The burden and management of TIA and stroke in the Veterans Administration and Department of Defense. Am J Manag Care. 2009;15(6 Suppl):S185-92.

[PMID: 19601694]

49. Jencks SF, Williams MV, Coleman EA. Rehospitalizations among patients in the Medicare fee-for-service program. N Engl J Med. 2009;360(14):1418-28. [PMID: 19339721] DOI:10.1056/NEJMsa0803563

50. Roby DH, Pourat N, Pirritano MJ, Vrungos SM, Dajee H, Castillo D, Kominski GF. Impact of patient-centered medical home assignment on emergency room visits among uninsured patients in a county health system. Med Care Res Rev. 2010;67(4):412-30. [PMID: 20519430] DOI:10.1177/1077558710368682

51. Hawton A, Green C, Dickens AP, Richards SH, Taylor RS, Edwards R, Greaves CJ, Campbell JL. The impact of social isolation on the health status and health-related quality of life of older people. Qual Life Res. 2010. [Epub ahead of print]. [PMID: 20658322]

Submitted for publication May 4, 2010. Accepted in revised form September 14, 2010.

This article and any supplementary material should be cited as follows:

Hubbard Winkler SL, Wu S, Cowper Ripley DC, Groer $\mathrm{S}$, Hoenig H. Medical utilization and cost outcomes for poststroke veterans who receive assistive technology devices from the Veterans Health Administration. J Rehabil Res Dev. 2011;48(2):125-34.

DOI:10.1682/JRRD.2010.05.0081

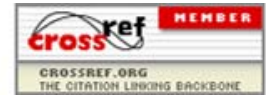


